\title{
THE SENSITIVITY ANALYSIS OF A MEMS MICROPHONE WITH DIFFERENT MEMBRANE DIAMETERS
}

\section{Cheng-Ta Yang}

Department of Marine Engineering, National Kaohsiung Marine University, Kaohsiung, Taiwan, R.O.C, albert.yang@mail.nkmu.edu.tw

\section{Recommended Citation}

Yang, Cheng-Ta (2010) "THE SENSITIVITY ANALYSIS OF A MEMS MICROPHONE WITH DIFFERENT MEMBRANE DIAMETERS," Journal of Marine Science and Technology. Vol. 18: Iss. 6, Article 2.

DOI: $10.51400 / 2709-6998.1936$

Available at: https://jmstt.ntou.edu.tw/journal/vol18/iss6/2

This Research Article is brought to you for free and open access by Journal of Marine Science and Technology. It has been accepted for inclusion in Journal of Marine Science and Technology by an authorized editor of Journal of Marine Science and Technology. 
THE SENSITIVITY ANALYSIS OF A MEMS MICROPHONE WITH DIFFERENT MEMBRANE DIAMETERS

Acknowledgements

The research was supported by National Science Council of Taiwan, R.O.C. under grant no. NSC

97-2221-E-022-008- MY2

This research article is available in Journal of Marine Science and Technology: https://jmstt.ntou.edu.tw/journal/ 


\title{
THE SENSITIVITY ANALYSIS OF A MEMS MICROPHONE WITH DIFFERENT MEMBRANE DIAMETERS
}

\author{
Cheng-Ta Yang*
}

Key words: MEMS microphone, sensitivity, diameter, coupling.

\begin{abstract}
In MEMS capacitive microphone design, it is very critical to get highest yielding rate and sensitivity as the two major factors dominate structure design of microphone. The centralpost MEMS microphone is introduced in this paper to differentiate from traditional fixed membrane boundary microphone since the construction is simple and only few masks are required in the process so that the yielding can be greatly enhanced. Thus, it is necessary to find the relationship between the sensitivity and dimension of the diameter of the membrane. The main research steps described in this paper include using CoventorWarer to develop one analysis model of MEMS microphone with coupled electro-mechanic system and analyzing the relationship between the sensitivity and the dimension of the diameter of the membrane.
\end{abstract}

\section{INTRODUCTION}

In recent years, micro electro mechanical systems (MEMS) technology is widely applied to design MEMS microphones. In 1992, Scheeper et al. [10] developed a novel capacitive microphone as shown in Fig. 1 and this design has been becoming a classical structure however larger residual stress was often introduced by fixed boundary. In 2000, Torkkeli et al. [11] developed a higher sensitivity microphone using low stress polysilicon fixed boundary membrane with $1 \mathrm{~mm}^{2}$ area but still have larger residual stress introduced by fixed boundary. In sensing mechanism, a capacitive microphone has higher sensitivity, stability and signal to noise ratio than piezoresistor and piezoelectric types [2]. For membrane material on MEMS capacitive microphone, metal, polysilicon, and $\mathrm{Si}_{3} \mathrm{~N}_{4}$ etc. are all applicable [8]. The successful application is to use polysilicon as membrane material on MEMS capacitive microphone due to lower coefficient of thermal expansion on polysilicon.

Paper submitted 07/30/09; revised 01/25/10; accepted 02/02/10. Author for correspondence: Cheng-Ta Yang (e-mail: albert.yang@mail.nkmu.edu.tw).

*Department of Marine Engineering, National Kaohsiung Marine University, Kaohsiung, Taiwan, R.O.C.
In 2008, Ganjia et al. [6] developed a new microphone by reducing acoustical resistance with perforated $\mathrm{Al}$ (aluminum) diaphragm to improve the sensitivity of microphone as shown in Fig. 2.

CoventorWare based on the finite element method is a well known software tool for efficient development in MEMS fields [4]. The capacitance of relative humidity ( $\mathrm{RH})$ sensor [7] as well as calibration data of the pressure sensor [5] is simulated by this software. Besides, the torsional varactor and capacitive ultrasonic transducers are simulated by this software [9, 12].

\section{SIMULATION METHOD}

\section{Comparison between the CoventorWare and Theoretical Models of Cantilever Beam with Rectangular Section}

A theoretical model of a cantilever beam with rectangular section is expressed as

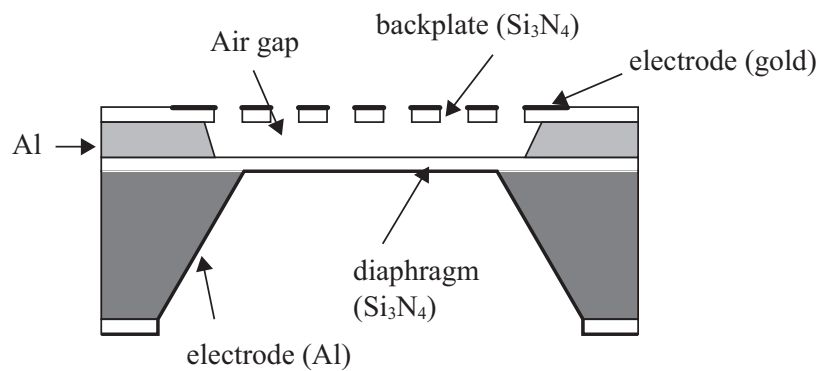

Fig. 1. Capacitive silicon microphone designed by Scheeper et al. [10].

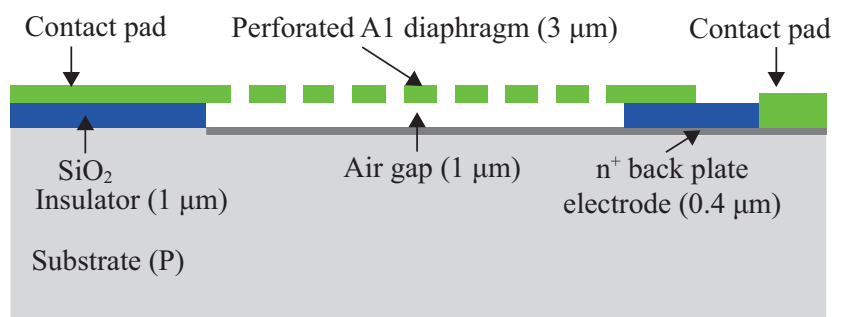

Fig. 2. Cross-sectional view of the microphone using a perforated aluminum diaphragm [6]. 
Table 1. Simulation parameters of a cantilever beam.

\begin{tabular}{|l|c|c|c|}
\hline \multicolumn{1}{|c|}{ parameters } & symbol & values & units \\
\hline \hline Young's modulus of beam (polysilicon) & $E$ & $1.58 \times 10^{5}$ & $\mathrm{MPa}$ \\
\hline beam width & $b$ & 30 & $\mu \mathrm{m}$ \\
\hline beam height & $h$ & 1.5 & $\mu \mathrm{m}$ \\
\hline beam length & $l$ & 300 & $\mu \mathrm{m}$ \\
\hline line pressure & $q$ & $-0.02 b$ & $\mathrm{~Pa}-\mu \mathrm{m}$ \\
\hline
\end{tabular}

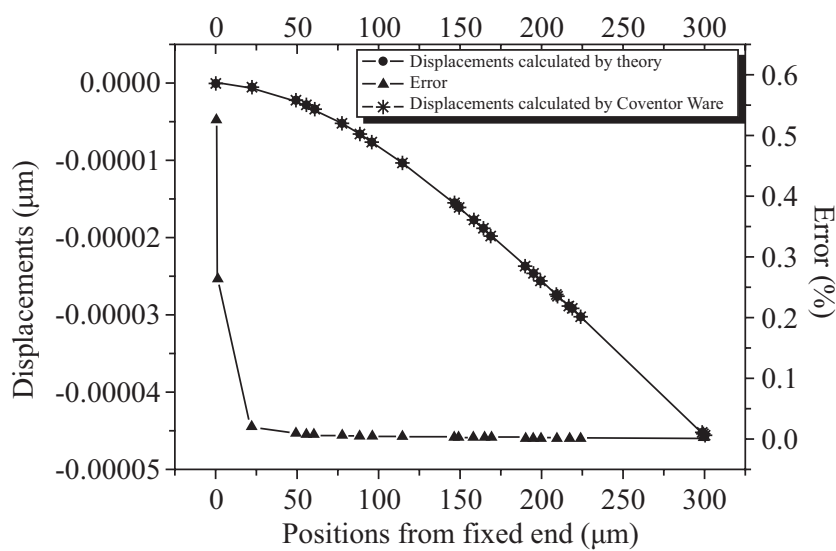

Fig. 3. Comparison between the CoventorWare and theoretical models of cantilever beam with rectangular section.

$$
\zeta=\frac{q}{24 E I}\left(x^{4}-4 l x^{3}+6 l^{2} x^{2}\right)
$$

where the parameters of the beam are shown in Table $1, \zeta$ is the lateral displacements, and the moment of inertia $I$ is expressed as (2).

$$
E=\frac{b h^{3}}{12}
$$

As shown in Fig. 3, the maximum error near the fixed end of the beam is $0.5 \%$. It is proved CoventorWare can be used in this study from the result showing the displacements of the beam simulated by CoventorWare is well agreement with those calculated by theoretical model.

\section{Compacted Model of a Central-Post Microphone}

The CoventorWare software is used for simulation and the steps shown in Fig. 4 are described as following:

(1) Setup material properties database.

(2) Setup process step.

(3) Design the layout.

(4) Build and mesh the solid model.

(5) Do mechanical and electrical coupling analysis.

(6) Output data.

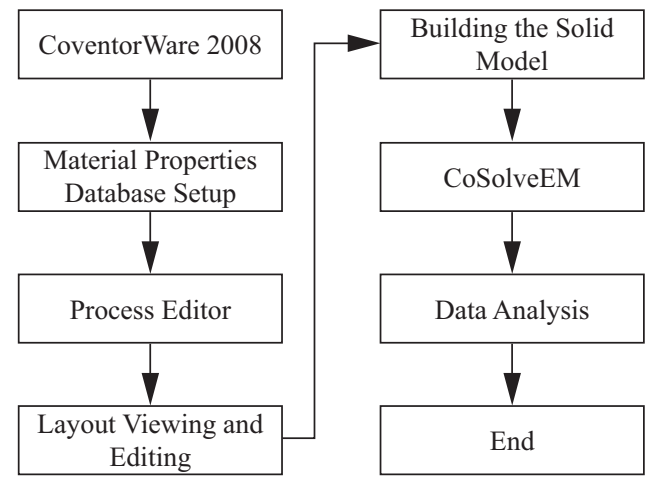

Fig. 4. Simulation flow of CoventorWare.
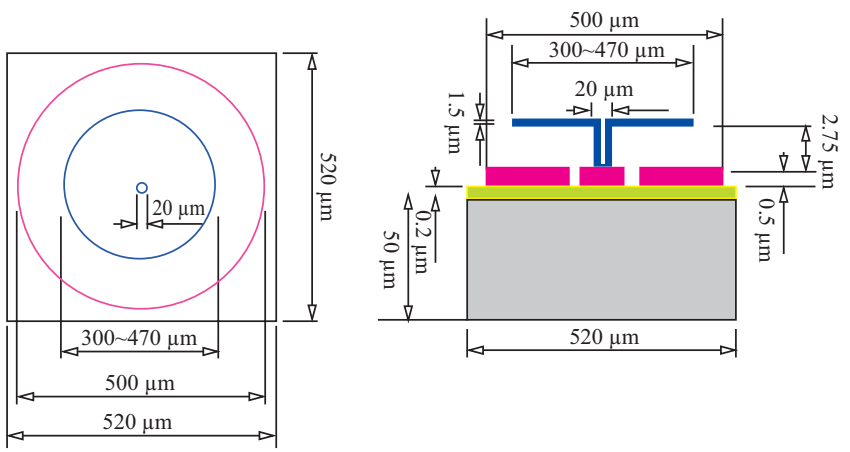

Fig. 5. Structure of a central-post MEMS microphone.
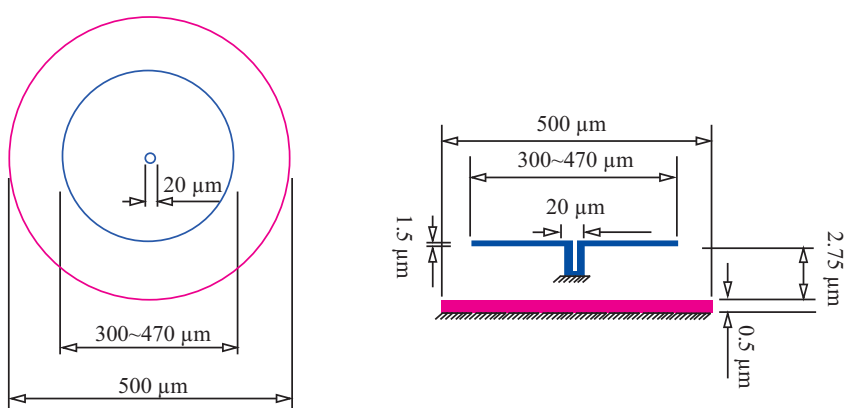

Fig. 6. Compacted model of a central-post microphone.

In this paper, we use mechanical and electrical coupling to analyze the sensitivity of membrane with 6 types of diameter. The original model is shown in Fig. 5 and will become compacted model with fixed lower-end central-post as shown in Fig. 6. The result is satisfying by using this compacted model to save much simulation time.

\section{STRUCTURE OF MICROPHONE AND MUMPS PROCESS}

The signal of a MEMS capacitive microphone comes from different output voltage caused by capacitance change of a pair of electrodes. The traditional fixed membrane boundary MEMS microphones have lower yielding which introduced by 
Table 2. Relationship between displacements in $Z$ direction and membrane diameters of 300-450 $\mu \mathrm{m}$.

\begin{tabular}{|c|c|c|c|c|c|c|}
\hline \multicolumn{7}{|c|}{$\begin{array}{l}\text { maximum displacements in } Z \text { direction }(\mu \mathrm{m}) \\
\text { thickness of membrane: } 1.5 \mu \mathrm{m} \text {; height of post: } 2.75 \mu \mathrm{m}\end{array}$} \\
\hline $\begin{array}{l}\text { pressure } \\
(\mathrm{Pa})\end{array}$ & 300 & 340 & 370 & 400 & 440 & 450 \\
\hline 0 & -0.089 & -0.151 & -0.221 & -0.318 & -0.520 & -0.592 \\
\hline 1 & -0.090 & -0.153 & -0.223 & -0.322 & -0.526 & -0.599 \\
\hline 2 & -0.091 & -0.155 & -0.226 & -0.325 & -0.532 & -0.606 \\
\hline
\end{tabular}

(1)

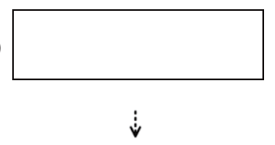

(2)

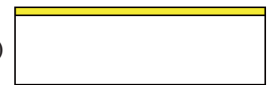

$\dot{i}$

(3)

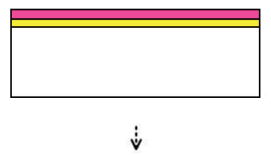

(4)

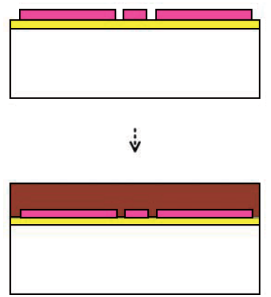

(6)

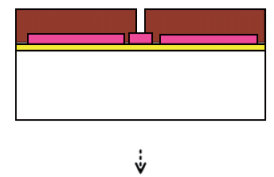

(7)

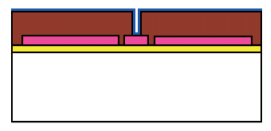

(8)

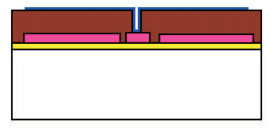

(9)

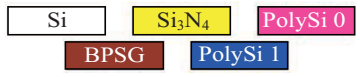

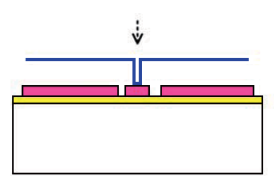

Fig. 7. Process flow of a central-post microphone.

larger residual stress in the membrane, long distance of the release path and a maximum deflection in the center of a membrane. The central-post MEMS microphone which is different from traditional fixed membrane boundary microphone is introduced in this paper to improve the yielding and to reduce the residual stress in the membrane.

\section{Structure of a Central-Post MEMS Microphone}

As shown in Table 2, 6 types of membrane diameters of a central-post microphone shown as compacted model in Fig. 6 is simulated by CoSolve EM analysis in this paper. Using the same sound pressure, analysis of the sensitivity change introduced by different membrane diameters of a central-post and free boundaries circular microphone is the major point in this paper. A central-post novel MEMS microphone with free boundary condition have been designed to reduce the residual stress and improve the sensitivity of the membrane [13]. The

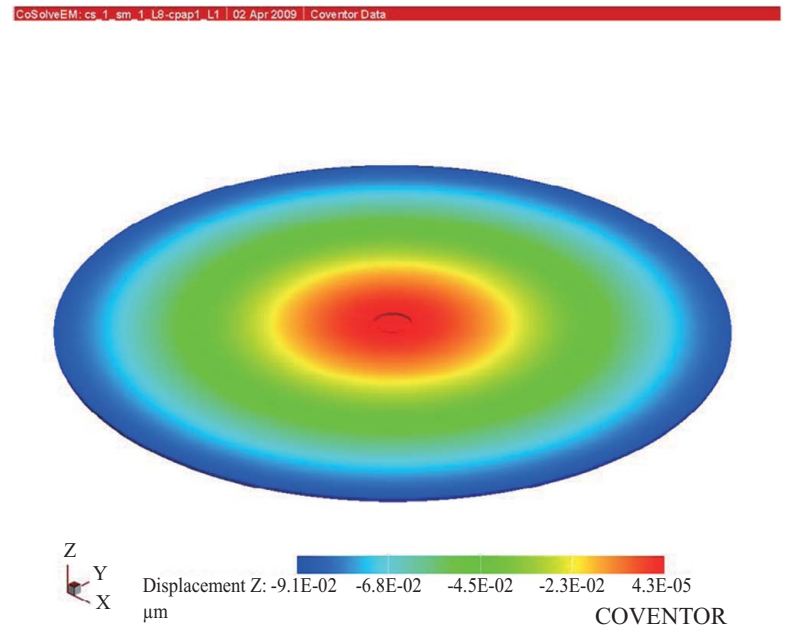

Fig. 8. Coupling analysis - the displacement distribution in $Z$ direction with a $300 \mu \mathrm{m}$ diameter of a membrane.

shorter release distance design is helpful to avoid the sticking between membrane and under-electrode so as to increase the process yield. The dimensions of a central-post microphone are shown in Fig. 5 in which the diameters of the membrane and the central-post of $2.75 \mu \mathrm{m}$ height are $300-470 \mu \mathrm{m}$ and 20 $\mu \mathrm{m}$, respectively.

The process flow is shown in Fig. 7 and described as following:

(1) Use $50 \mu \mathrm{m} \mathrm{Si}$ as the substrate.

(2) Deposit an isolation layer of $0.2 \mu \mathrm{m} \mathrm{Si}_{3} \mathrm{~N}_{4}$.

(3) Deposit a under-electrode layer of $0.5 \mu \mathrm{m}$ PolySi 0.

(4) Define the under-electrode using the first mask.

(5) Deposit a sacrificial layer of $2.75 \mu \mathrm{m}$ BPSG.

(6) Define the sacrificial layer using the second mask.

(7) Deposit a membrane of $1.5 \mu \mathrm{m}$ PolySi 1.

(8) Define the membrane using the third mask.

(9) Release the membrane and finish the central-post capacitive microphone.

\section{CHARACTERISTIC ANALYSIS OF A CENTRAL-POST MICROPHONE}

The characteristic of a central-post microphone was simulated with a nonlinear method of CoventorWare software.

\section{Coupling Analysis between the Electrical and Mechanical Characteristic of the Central-Post Microphone}

In the coupling analysis between the electrical and mechanical characteristic of the central-post microphone, the capacitance and its change are calculated with 2 types of sound pressure, 6 types of membrane diameters and 3 types of membrane thicknesses. When $12 \mathrm{~V}$ bias voltage and $0 \mathrm{~Pa}$ uniform pressure are applied on the membrane of $300 \mu \mathrm{m}$ diameter as shown in Fig. 8, the distribution of the out-of-plane ( $Z$ direc- 


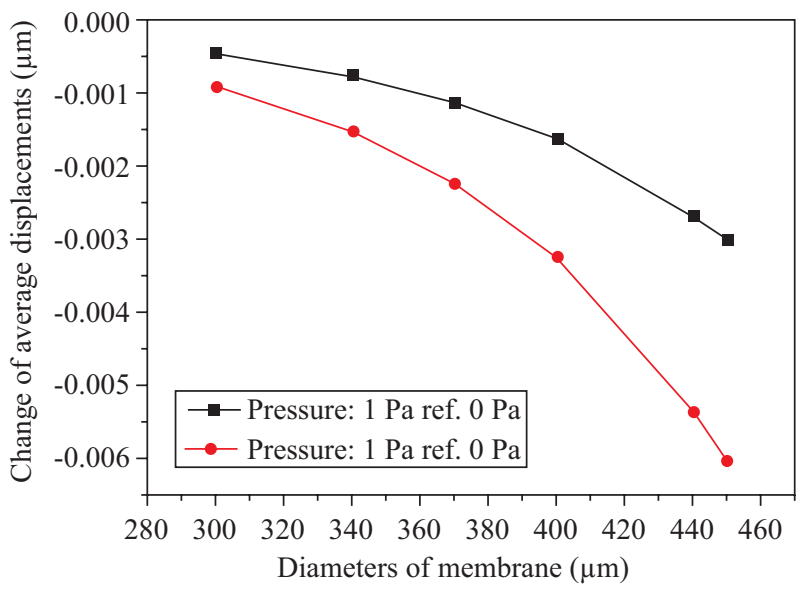

Fig. 9. Change of average displacement with variant diameter (membrane thickness $=1.5 \mu \mathrm{m}$ ).

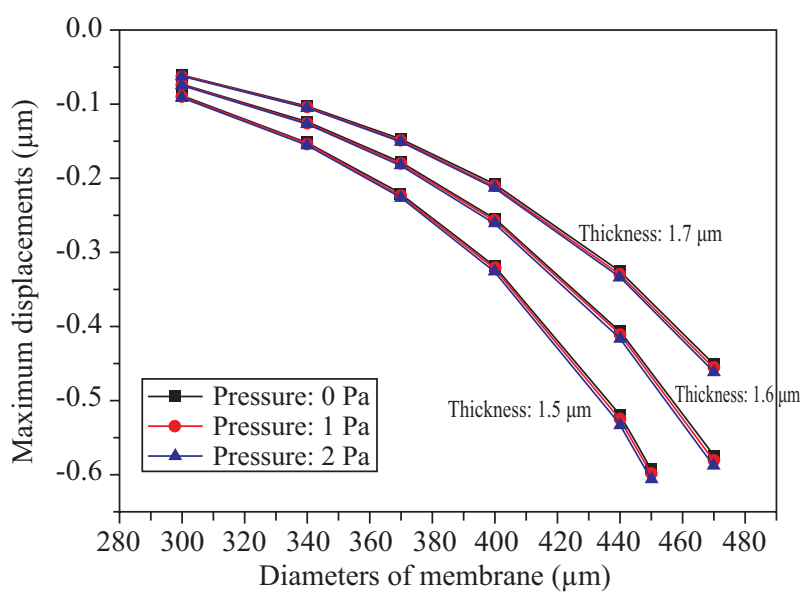

Fig. 10. Maximum displacement curves with variant diameter.

tion) displacement shown as mushroom shape has smallest displacement in the center of the membrane and is increasing with the increasing radius.

\section{Relationship between the Displacements and the Diameter of the Membrane}

When $12 \mathrm{~V}$ bias voltage and $0 \mathrm{~Pa}, 1 \mathrm{~Pa}$ and $2 \mathrm{~Pa}$ uniform sound pressures are applied on the membrane of 6 different diameters, the out-of-plane displacement around the edge of the membrane is the largest. As shown in Table 2, the largest displacement around the edge of the membrane is increased with increasing diameter and sound pressure.

In central-post microphone design, the membrane is supported by a post and the average displacements are calculated in $1 \mathrm{~Pa}$ and $2 \mathrm{~Pa}$ sound pressure referring to $0 \mathrm{~Pa}$ as a reference point and only the cross section data is calculated while the post data is disregarded in this calculation. As shown in Figs. 9 and 10, the change of average displacements and the maximum displacements are nonlinearly increased with the increasing sound pressure and membrane diameter.

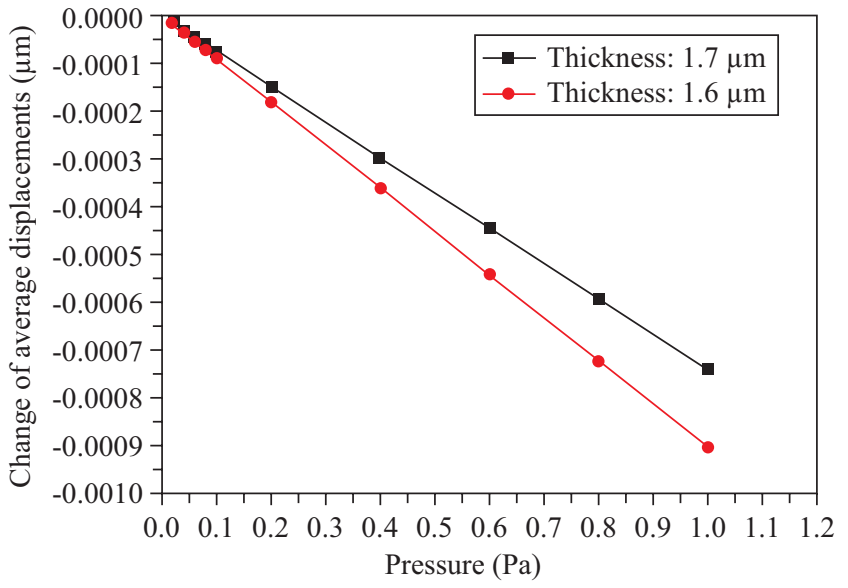

Fig. 11. Change of average displacement with variant pressure (membrane diameter $=370 \mu \mathrm{m})$.

The displacement of the membrane is increased with the increasing membrane diameter to enhance sensitivity of microphone. However, the membrane cannot be increased without any limitation as it may cause breakdown due to instability when the membrane deflection is $1 / 3$ of the distance between the two electrodes [3]. In addition, the post height (i.e. the distance between the two electrodes) and membrane thickness are another two major factors in microphone design. As shown in Table 2, $12 \mathrm{~V}$ bias voltage is applied and the maximum displacement of the membrane with $1.5 \mu \mathrm{m}$ thickness and $450 \mu \mathrm{m}$ diameter is $0.606 \mu \mathrm{m}$. This data is close to $0.917 \mu \mathrm{m}(2.75$ $\mu \mathrm{m} / 3$ ) that apply no bias voltage and may cause the breakdown.

The sensitivity of a membrane is calculated by the change of average displacements which is simulated with nonlinear method of CoventorWare software. As shown in Fig. 11, the linear curves calculated from the nonlinear simulative method will show that the structure of the central-post microphone subjected to the sound pressures of $0-1 \mathrm{~Pa}$ is in the linear behavior region. We can use the inner interpolation method to calculate any change of average displacements in the sound pressures of $0-1 \mathrm{~Pa}$. This method will reduce the simulation time and data that need to be analyzed.

\section{Sensitivity Analysis of the Capacitive Microphone}

The sensitivity of a microphone in two types of sound pressure $1 \mathrm{~Pa}$ and $2 \mathrm{~Pa}$ [1] can be expressed as

$$
S=\frac{U_{0}}{h} \frac{\Delta h}{\Delta P} \frac{1}{\left(1+C_{s} / C_{m}\right)} \quad[\mathrm{V} / \mathrm{Pa}]
$$

where $U_{0}$ is the bias voltage, $h$ is the distance between the two electrodes, $\Delta h$ is the deviation of $h, \Delta P$ is the deviation of the applied sound pressure, $C_{m}$ is the microphone working capacitance, and $C_{s}$ are stray capacitances in the microphone as well as in the preamplifier. When the open-circuit sensitivity $S$ is calculated, the stray capacitances $C_{s}$ can be reduced to 0 [1]. 
Table 3. Simulation parameters of a central-post microphone.

\begin{tabular}{|l|c|c|}
\hline \multicolumn{1}{|c|}{ parameters } & values & units \\
\hline \hline Young's modulus of membrane (polysilicon) & $1.58 \times 10^{5}$ & $\mathrm{MPa}$ \\
\hline density of membrane (polysilicon) & $2.23 \times 10^{-15}$ & $\mathrm{~kg} / \mu \mathrm{m}^{3}$ \\
\hline air gap & 2.75 & $\mu \mathrm{m}$ \\
\hline permittivity of free space & $8.85 \times 10^{-12}$ & $\mathrm{~F} / \mathrm{m}$ \\
\hline thickness of membrane & 1.5 & $\mu \mathrm{m}$ \\
\hline diameters of membrane (6 types) & $300-450$ & $\mu \mathrm{m}$ \\
\hline
\end{tabular}

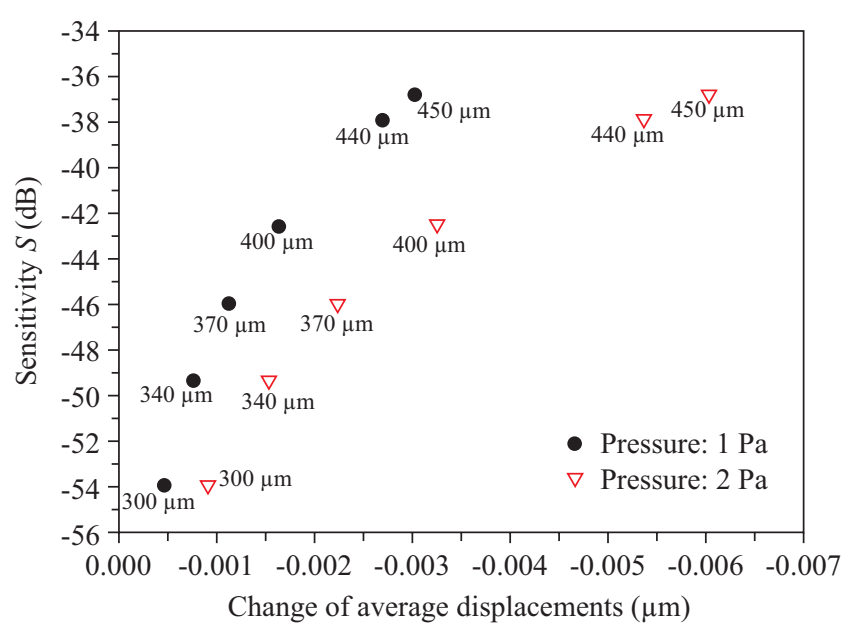

Fig. 12. Sensitivity vs. change of average displacement (membrane diameters $=300-450 \mu \mathrm{m}$ ).

Microphone diameter, bias voltage, sound pressure, and the distance between two electrodes are the major factors for the microphone sensitivity calculation. In this research, we use 0 $\mathrm{Pa}$ sound pressure and $0 \mathrm{~Pa}$ displacements as a reference point to calculate the $\Delta P$ and $\Delta h$, respectively. The microphone dimensions and material properties are shown in Table 3 . Based on the axissymmetrical theory, the change of average displacements in $1 \mathrm{~Pa}$ and $2 \mathrm{~Pa}$ sound pressure $(0 \mathrm{~Pa}$ is the reference point) is calculated by the displacements in the $+X$ direction.

As shown in Fig. 12, the sensitivity increases from -53.9 to $-36.8 \mathrm{~dB}$ due to diameters increase from 300 to $450 \mu \mathrm{m}$. The change of average displacements increases from -0.00045 to $-0.00302 \mu \mathrm{m}$ in $1 \mathrm{~Pa}$ and from -0.00091 to $-0.00603 \mu \mathrm{m}$ in $2 \mathrm{~Pa}$ due to diameter increase from 300 to $450 \mu \mathrm{m}$. As shown in Figs. 12 and 13, it is important to address that the sensitivity is the same under different pressures and its trend is nonlinearly increasing the change of average displacements and membrane diameters.

\section{Characteristic Prediction of the Capacitive Microphone}

In condition of $2.75 \mu \mathrm{m}$ post height, the relationship curves between the membrane diameters and maximum displacements of $0 \mathrm{~Pa}$ in 3 types of membrane thickness are shown in

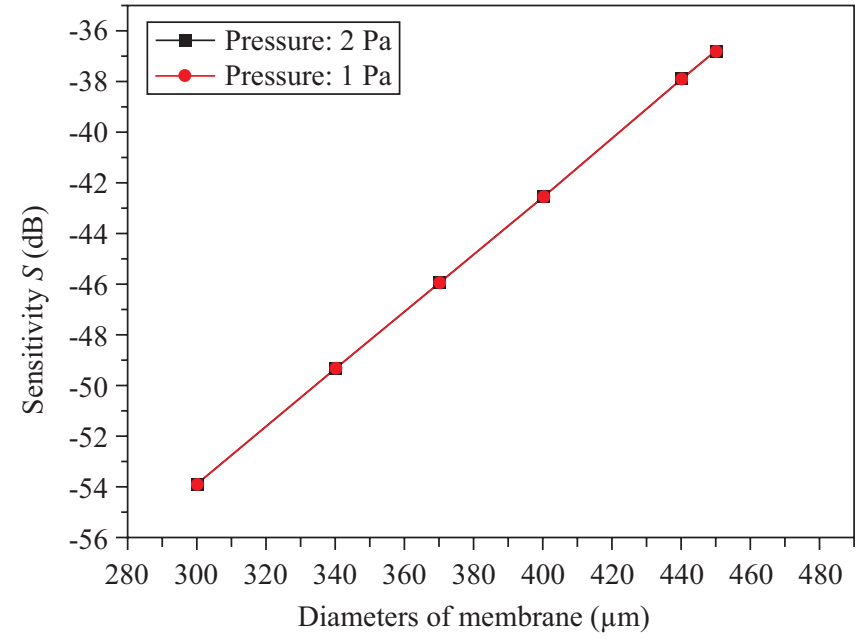

Fig. 13. Sensitivity curves with variant diameters (membrane thickness = $1.5 \mu \mathrm{m})$.

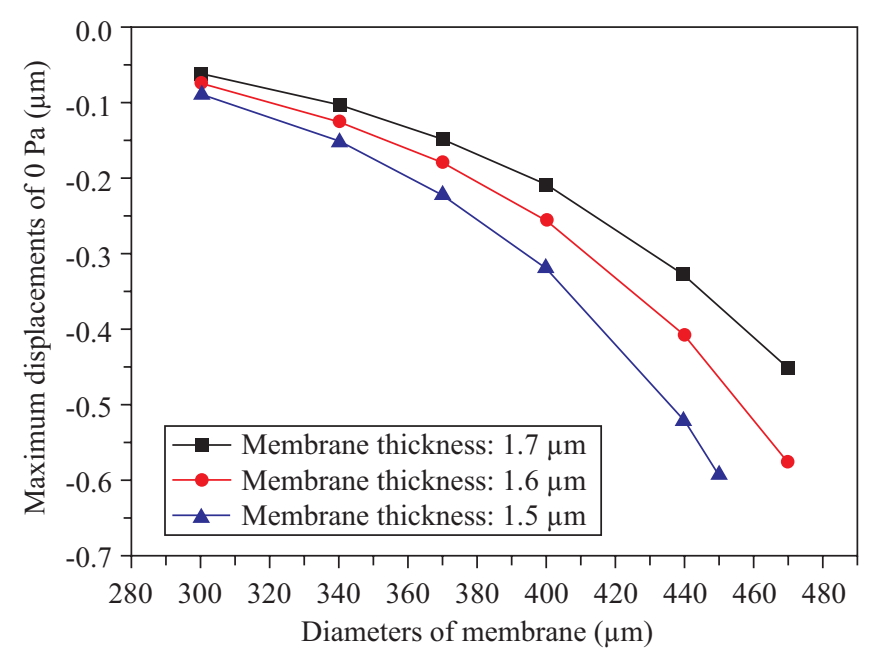

Fig. 14. Maximum displacements of $0 \mathrm{~Pa}$ with variant diameter.

Fig. 14. We extract the curve of $1.5 \mu \mathrm{m}$ thickness from Fig. 14 to come out the curve fitting equation (4) as shown in Fig. 15. In this equation, $\mathrm{x}$ is the diameter of the membrane and $\mathrm{y}$ is the maximum displacements. As shown in Fig. 15, the two curves are very closed and the unstable and breakdown maximum diameter of $490 \mu \mathrm{m}$ calculated by the curve fitting curve drop to the $1 \mu \mathrm{m}$ displacement, which is over the $1 / 3$ of $2.75 \mu \mathrm{m}$ post height.

$$
\begin{aligned}
y= & x^{3}\left(-8.7496362 \times 10^{-8}\right)+x^{2}\left(7.9587852 \times 10^{-5}\right) \\
& -x\left(2.5631233 \times 10^{-2}\right)+2.8006748
\end{aligned}
$$

For optimum design, the above-mentioned inner interpolation method and the curve fitting equation (4) can be used to calculate the maximum displacement and the breakdown displacement in any sound pressure. 


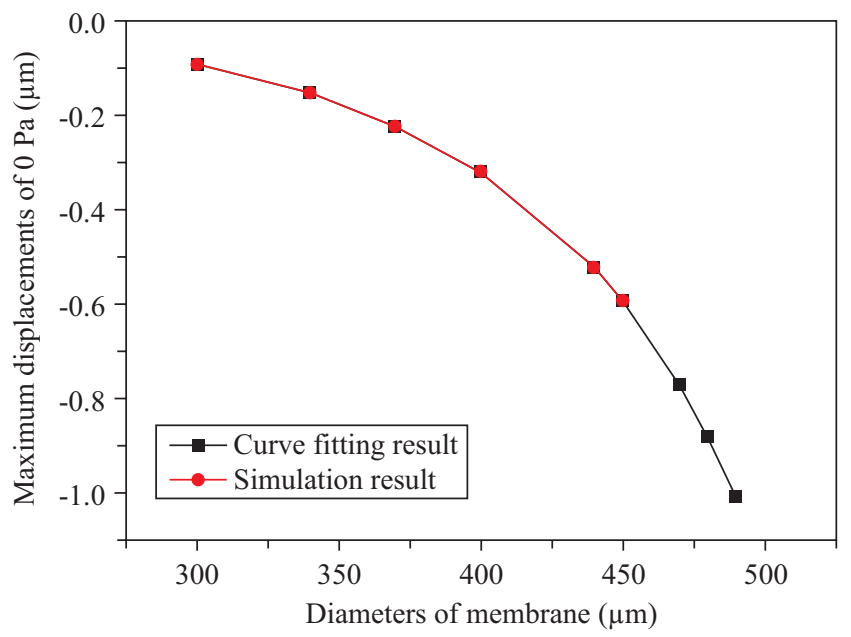

Fig. 15. Comparison between curve fitting and simulation results (membrane thickness: $1.5 \mu \mathrm{m}$ ).

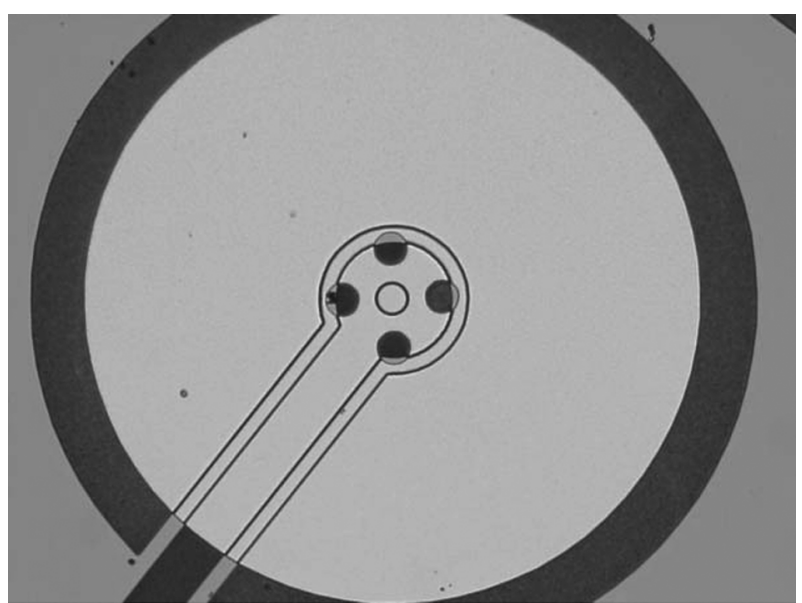

Fig. 16. The feature of the central-post microphone.

\section{CAPACITANCE-BIAS VOLTAGE CURVES OF CENTRAL-POST AND FIXED ENDS MICROPHONES}

An experimental feature of the central-post microphone fabricated with MUMPs process is shown in Fig. 16 and the capacitance-bias voltage $(\mathrm{C}-\mathrm{V})$ curves of this microphone are shown in Fig. 17. When the bias voltage is from -2.3 to $2.3 \mathrm{~V}$, the maximum change of capacitance in Torkkeli's [11] and this paper is $0.84 \mathrm{pF}$ and $0.85 \mathrm{pF}$, respectively. The $\mathrm{C}-\mathrm{V}$ curve of the fixed ends microphone with $1 \times 1 \mathrm{~mm}^{2}$ membrane in Torkkeli's paper is measured by $1 \mathrm{MHz}$ and $10 \mathrm{mV}$ AC voltage and that of the central-post microphone with $370 \mu \mathrm{m}$ membrane diameter in this paper is measured by $1 \mathrm{MHz}$ and 250 $\mathrm{mV}$ AC voltage.

\section{CONCLUSION}

(1) The sensitivity of a central-post microphone with a $1.5 \mu \mathrm{m}$

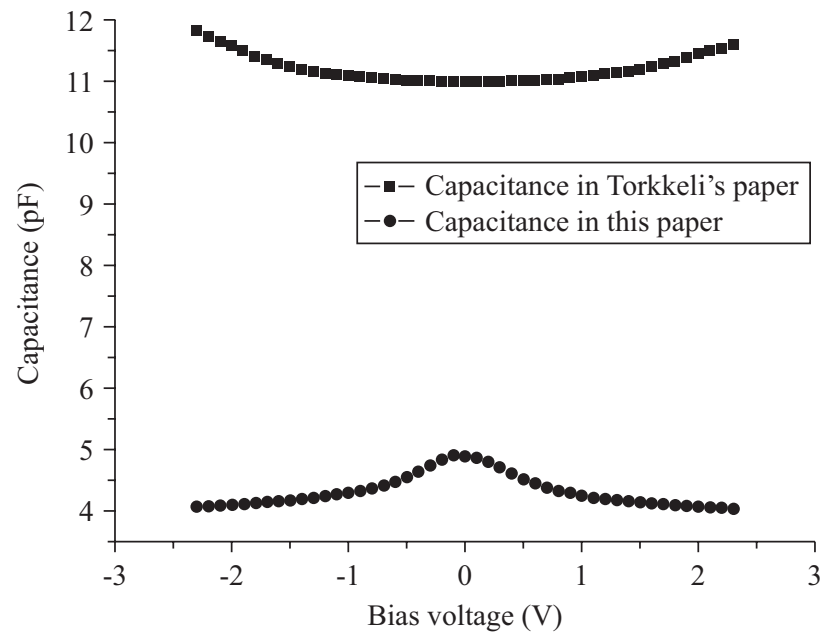

Fig. 17. C-V curves of central-post and fixed ends microphones.

membrane thickness and $2.75 \mu \mathrm{m}$ post height subjected to $1 \mathrm{~Pa}$ sound pressure on the membrane surface is nonlinearly increased from -53.9 to $-36.8 \mathrm{~dB}$ while increasing the membrane diameters from 300 to $450 \mu \mathrm{m}$. As long as no breakdown voltage occurs, increasing membrane diameters can greatly enhance the sensitivity of microphone.

(2) We can use the timesaving inner interpolation method to calculate any change of average displacements in the sound pressures of 0-1 $\mathrm{Pa}$ because the displacements are linearly increased in this sound pressure level. This method can be used to do optimum design of a MEMS microphone.

(3) The maximum change of capacitance in the central-post microphone with $370 \mu \mathrm{m}$ membrane diameter and the fixed ends microphone with $1 \times 1 \mathrm{~mm}^{2}$ membrane is pretty close.

\section{ACKNOWLEDGMENTS}

The research was supported by National Science Council of Taiwan, R.O.C. under grant no. NSC 97-2221-E-022-008MY2.

\section{REFERENCES}

1. Bergqvist, J., "Finite-element modelling and characterization of a silicon condenser microphone with a highly perforated backplate," Sensors and Actuators A, Vol. 39, pp. 191-200 (1993).

2. Chen, J., Liu, L., Li, Z., Tan, Z., Xu, Y., and Ma, J., "On the single-chip condenser miniature microphone using DRIE and back side etching techniques," Sensors and Actuators A, Vol. 103, pp. $42-47$ (2003).

3. Chen, J. S., Design and Fabrication of a Silicon Microphone, Master Thesis, Department of Electrical and Control Engineering, National Chiao Tung University, Hsinchu, Taiwan (2000).

4. CoventorWare V2008, http://www.coventor.com.tw.

5. Dimitropoulos, P. D., Kachris, C., Karampatzakis, D. P., and Stamoulis, G. I., "A new SOI monolithic capacitive sensor for absolute and differential pressure measurements," Sensors and Actuators A, Vol. 123-124, pp. 36-43 (2005).

6. Ganjia, B. A. and Majlis, B. Y., "Design and fabrication of a new MEMS capacitive microphone using a perforated aluminum diaphragm," Sensors 
and Actuators A, Vol. 149, pp. 29-37 (2008)

7. Hautefeuille, M., O’Mahony, C., O’Flynn, B., Khalfi, K., and Peters, F., "A MEMS-based wireless multisensor module for environmental monitoring," Microelectronics Reliability, Vol. 48, pp. 906-910 (2008).

8. Qiao, D. H., Tian, J., Xu, L., and Wang, C. H., "A micro-machined condenser microphone with polysilicon diaphragm," (in Chinese), China Mechanical Engineering, Vol. 16, No. 14, pp. 1243-1246 (2005).

9. Sato, M., Hirai, Y., Sugano, K., Tsuchiya, T., and Tabata, O., "Capacitive micromachined ultrasonic transducers with novel membrane design," Procedia Chemistry, Vol. 1, pp. 389-392 (2009).

10. Scheeper, P. R., van der Donk, A. G. H., Olthuis, W., and Bergveld, P., "Fabrication of silicon condenser microphone using single wafer tech- nology," The Journal of Microelectromechanical Systems, Vol. 1, No. 3, pp. 147-154 (1992).

11. Torkkeli, A., Rusanen, O., Saarilahti, J., Seppa, H., Sipola, H., and Hietanen, J., "Capacitive microphone with low-stress polysilicon membrane and high-stress polysilicon backplate," Sensors and Actuators A, Vol. 85, pp. 116-123 (2000).

12. Venkatesh, C., Pati, S., Bhat, N., and Pratap, R., "A torsional MEMS varactor with wide dynamic range and low actuation voltage," Sensors and Actuators A, Vol. 121, pp. 480-487 (2005).

13. Yang, C. T. and Huang, L. J., "Design of a novel MEMS capacitive microphone," (in Chinese), 25th National Conference on Mechanical Engineering, Changhua, Taiwan, pp. 564 (2008). 